Full Research Paper

\title{
Potentiometric Responses of Ion-Selective Electrodes Doped with Diureidocalix[4]arene towards Un-dissociated Benzoic Acid
}

\author{
Agnieszka Krajewska ${ }^{1}$, Pavel Lhotak ${ }^{2}$ and Hanna Radecka ${ }^{1, *}$ \\ ${ }^{1}$ Institute of Animal Reproduction and Food Research, Polish Academy of Sciences Tuwima 10, \\ 10-747 Olsztyn, Poland \\ E-mail: hanna.radecka@pan.olsztyn.pl \\ ${ }^{2}$ Department of Organic Chemistry, Institute of Chemical Technology, Technicka 5, 16628 Prague 6, \\ Czech Republic
}

* Author to whom correspondence should be addressed.

Received: 5 July 2007 / Accepted: 26 August 2007 / Published: 27 August 2007

\begin{abstract}
Diureidocalix [4] arene have been applied as new ionophore in liquid membrane electrode (ISE) sensitive towards un-dissociated benzoic acid. The electrode demonstrated response towards benzoic acid with the detection limit $2.0 \times 10^{-4} \mathrm{M}$ which is sufficient for the determination of benzoic acid added to beverages as preservative in milimolar concentration. The selectivity coefficients measured by the matched potential method (MPM) showed its good selectivity against common anions present in drink samples. All measurements were made in presence of $1.0 \times 10^{-2} \mathrm{M} \mathrm{NaHSO}_{4} \mathrm{pH} 3.0$ in order to reduce the influence of $\mathrm{OH}^{-}$. The applicability of diureidocalix[4]arene incorporated ISE has been checked by recovery test of benzoic acid in the presence of artificial drink matrix and by standard addition method.
\end{abstract}

Keywords: Diureidocalix[4]arene, Liquid membrane electrodes, Benzoic acid, Drink analysis.

\section{Introduction}

Calixarenes are macrocyclic compounds widely used in supramolecular chemistry for charged and neutral compounds recognition $[1,2]$. These macrocycles, belonging to the class of compounds named 
cavitands, posses 'cup' like shape characterized by wide upper and narrow lower rims and central annulus. They have hydrophobic cavities which can complex small molecules or ions. It was showed that simple unfunctionalized calix[4]arene, like p-tert-butylcalix[4]arene, can interact with amines [3]. Calix[4]arenes and calix[6] arenes possess cavities suitable for $\mathrm{Na}^{+}$and $\mathrm{Cs}^{+}$complexation, respectively [4]. It has been reported that in the pores of silica calix[n]arenes $(n=4,6,8)$ form supramolecular complexes with $\mathrm{C}_{60}$ [1]. Calix[4]arene possesses wide derivatisation possibilities and consequently, its upper and lower rims can be easily modified to yield various versatile receptors [5]. The introduction of amide, urea and thiourea moieties into the upper rim of calixarene and preorganisation in the cone conformation form receptors enabling the binding of anions by hydrogen bonds $[6,7]$.

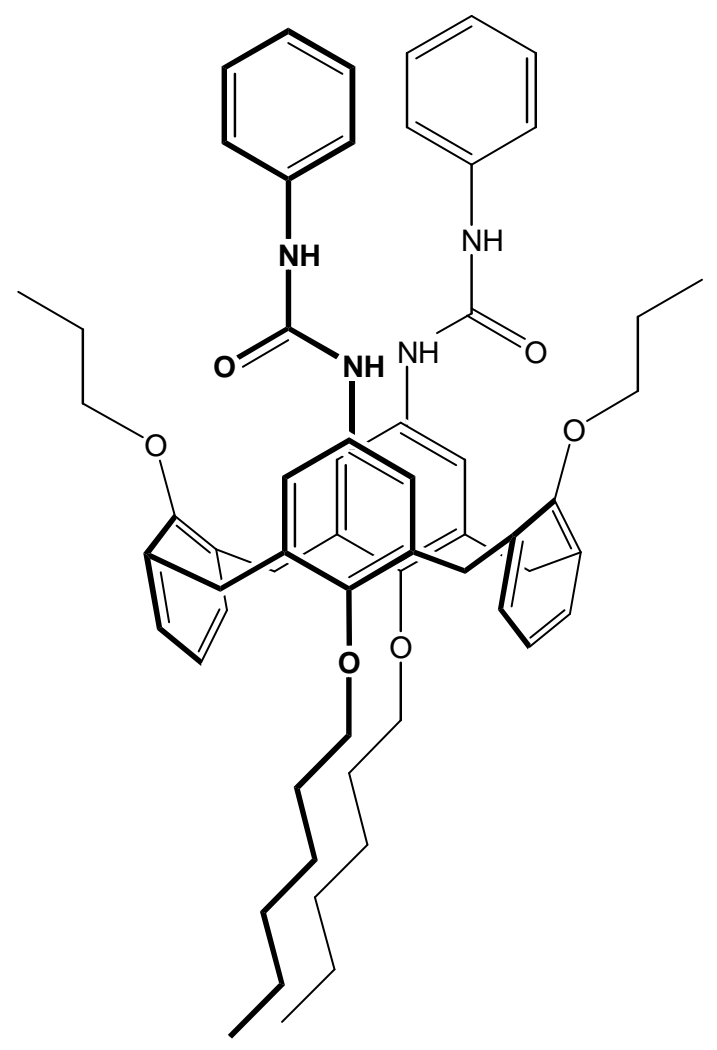

Figure 1. The structure of diureidocalix[4]arene.

Biscalix[4]arenes in which the upper rim of one calixarene moiety is covalently linked via amide bonds to the lower rim of another can bind $\mathrm{F}^{-}$[8]. The 1,3 alternate conformers can possess two independent ionophoric sites on either side of the cavity, but it has been proved that diureido derivatives of calix[4]arenes in 1,3-alternate conformer, such as investigated in this work, represents ionophores with one possible binding site and exhibit binding affinity towards selected anions. Similar calixarene with two ureido moieties were used to measure the complexation ability in organic solution by standard ${ }^{1} \mathrm{H}$ NMR titration experiments using constant concentration of receptor and increasing concentrations of the appropriate anions. These investigations showed strong interaction with benzoate anions (probably because of additional interactions between aromatic parts of receptor and analyte), while the complexation constants towards chloride, acetate and phosphate are much lower [9]. Thus, such a type of receptors might be suitable for sensing benzoic acid. 
This acid and its sodium salt are used as food preservatives. It is the most suitable for fruit juices and soft drinks which posses acidic $\mathrm{pH}$ [10].

Analytical methods used for determination of benzoic acid include spectroscopic technique [11, 12], gas chromatography (GC) [13, 14], high performance liquid chromatography (HPLC) [15, 16] or capillary electrophoresis [17]. All of them involve extensive extraction procedures which are timeconsuming and expensive.

In this paper we propose a potentiometric sensor based on a ISE incorporating diureidocalix[4]arene (1,3-alternate conformer, which posses only one binding site), for the direct and rapid determination of un-dissociated benzoic acid in drink samples.

\section{Materials and Methods}

\subsection{Reagents}

The diureidocalix[4]arene used as ionophore was synthetised according to procedure already published [5] and the experimental details will be published elsewhere.

High molecular weight poly(vinyl chloride) (PVC) used as polymer matrix was purchased from Wako Pure Chemical (Japan). Dioctyl phthalate (DOP) used as membrane solvent and tri(dodecyl)methylammonium chloride (TDDMACl) were obtained from Aldrich Chemie, Germany. Potassium tetrakis(4-chlorophenyl)borate (K-TpClPB) was obtained from Dojindo Laboratories (Kumamoto, Japan), benzoic acid from Serva (Germany), sulfuric acid, sodium sulfate, glucose, sodium chloride, sodium bromide, acetic acid, ascorbic acid, citric acid, phosphate monosodium salt were purchase from POCh (Gliwice, Poland). Tetrahydrofuran (THF) was purchased from POCh (Gliwice, Poland) and used freshly distilled from solid $\mathrm{NaOH}$.

Aqueous solution were prepared with deionized water (18.2 $\mathrm{M} \Omega$ resistivity) obtained with a Simplicity ${ }^{\circledR} 185$ Water System (Millipore, Molsheim, France).

\subsection{Membranes and Electrodes Preparation}

Polymeric liquid membranes were prepared according to the standard procedure. The membranes consist of: ca. $1 \mathrm{wt} \%$ receptor, $66 \mathrm{wt} \%$ DOP and $33 \mathrm{wt} \%$ PVC. Some membranes were additionally incorporated with $50 \mathrm{~mol} \%$ (versus receptor) of lipophilic salt TDDMACl or K-TpCIPB.

All components were dissolved in about $2 \mathrm{ml}$ of THF and resulting solution was transferred to the glass ring (diameter $30 \mathrm{~mm}$ ) and left for $48 \mathrm{~h}$ to evaporate the solvent. The membrane circles (diameter $6 \mathrm{~mm}$ ) were then cut out and placed in the liquid membrane-type Philips ISE body (Glasbläserei Möller, Zürich). Electrodes were conditioned for $24 \mathrm{~h}$ in an aqueous solution of $1.0 \times 10^{-2} \mathrm{M} \mathrm{NaHSO}_{4}$.

The cell assembly for potentiometric measurements was as follows:

$\mathrm{Ag} / \mathrm{AgCl}, 3 \mathrm{M} \mathrm{KCl}\left|1 \mathrm{M} \mathrm{CH}_{3} \mathrm{COOLi}\right|$ sample solution | modified PVC membrane $\mid 0.1 \mathrm{M} \mathrm{KCl}$ | $\mathrm{Ag} / \mathrm{AgCl}$ 


\subsection{EMF Measurements}

Potentiometric measurements were made using a multi-channel station Donau-Lab (Warsaw, Poland) at room temperature. The reference electrode was a double junction $\mathrm{Ag} / \mathrm{AgCl}, 3 \mathrm{M} \mathrm{KCl} \mid 1 \mathrm{M}$ $\mathrm{CH}_{3} \mathrm{COOLi}$ electrode obtained from Philips. The $\mathrm{pH}$ values were monitored using glass electrode $\mathrm{HI}$ 1139 obtained from Hanna Instruments. The effect of the $\mathrm{pH}$ changes from 2.5 to 9.5 on the membrane potential was measured by addition of $1.0 \times 10^{-1} \mathrm{M} \mathrm{NaOH}$ solution containing $1.0 \times 10^{-2} \mathrm{M} \mathrm{Na}_{2} \mathrm{SO}_{4}$ to a solution of $1.0 \times 10^{-2} \mathrm{M} \mathrm{H}_{2} \mathrm{SO}_{4}$. The effect of $\mathrm{pH}$ changes from 9.5 to 2.5 was measured by addition of $1.0 \times 10^{-1} \mathrm{M} \mathrm{H}_{2} \mathrm{SO}_{4}$ solution containing $1.0 \times 10^{-2} \mathrm{M} \mathrm{NaHSO}_{4}$ to a solution of $1.0 \times 10^{-2} \mathrm{M} \mathrm{NaOH}$.

Calibration curves were constructed by plotting the observed changes in potential vs the logarithm of benzoic acid concentration at constant $\mathrm{pH}$. The selectivity coefficients $\left(\log K_{B e n z, j}^{M P M}\right)$ were determined by the matched potential method (MPM) in mixed solutions [18-20].

The recovery test was done using juice matrix with the following typical composition: $1.0 \times 10^{-2} \mathrm{M}$ citric acid and $2.5 \mathrm{~g}$ glucose/L [21].

The contents of benzoic acid were analysed in lemon soft drink Hoop (produced by HOOP S.A) to which this compound was added as preservative. The composition of measured beverage declared by producer included sugar, glucose-fructose syrup, $\mathrm{CO}_{2}$, citric acid and sodium citrate as acidity regulators, aroma, ascorbic acid, sodium benzoate. The beverage was degassed in an ultrasonic bath for $20 \mathrm{~min}$ before use. The determination of benzoic acid was carried out using the standard addition method, which involved the addition of $1 \mathrm{ml}$ aliquots of a $1.0 \times 10^{-2} \mathrm{M}$ benzoic acid stock solution to a $100 \mathrm{ml}$ of aqueous solution of $1.0 \times 10^{-2} \mathrm{M} \mathrm{Na}_{2} \mathrm{SO}_{4}$ containing $10 \mathrm{vol} \%$ of beverage. The membrane potential was recorded after each addition [22, 23].

\section{Results and Discussion}

\subsection{Potential Response of ISEs Incorporating Diureidocalix[4]arene towards pH Changes.}

The responses of ISEs towards $\mathrm{pH}$ changes in aqueous solution are very important parameters, which allow to optimized the measuring conditions of selected analytes and explored the mechanism of the potentiometrc responses.

The membrane modified only with diureidocalix[4]arene showed potentiometric response in relation to $\mathrm{pH}$ change of aqueous solution in range from 2.5 to $9.5 \mathrm{pH}$ unit. This phenomenon was completely reversible. The $\mathrm{pH}$ changes from 9.5 to 2.5 caused the same potential response.

In order to elucidate the nature of the response of diureidocalix[4]arene-ISE towards $\mathrm{pH}$ changes, membranes were additionally incorporated with anionic and cationic lipophilic salts. The presence of anionic sites in membrane caused a lack of its response towards $\mathrm{pH}$ (Figure 2). Large lipophilic anion $\mathrm{TpClPB}^{-}$hindered the ionophore- $\mathrm{OH}^{-}$complex formation probably because of electrostatic repulsion. On the other hand, cationic salt additive improved the $\mathrm{pH}$ response of diureidocalix[4]arene-ISE. The presence of large lipophilic cation $\mathrm{TDDMA}^{+}$facilitated formation of ionophore-OH- complex. Diureidocalix[4]arene is neutral ionophore and addition of cationic sites, with the charge sign opposite to that of $\mathrm{OH}^{-}$anion, to the membrane composition is effective in improving the electrodes response towards this anion [24-27]. 
Thus, it might be concluded that the potentiometric responses of diureidocalix[4]arene-ISE towards $\mathrm{pH}$ changes of aqueous solution occurred due to complexation of $\mathrm{OH}^{-}$by receptor molecules at the organic/aqueous interface.

The similar phenomenon was observed for ISE incorporating calix[4]pyrroles [28].

Figure 2 shows the potential changes of ISEs studied vs. $\mathrm{pH}$ changes in aqueous solution.

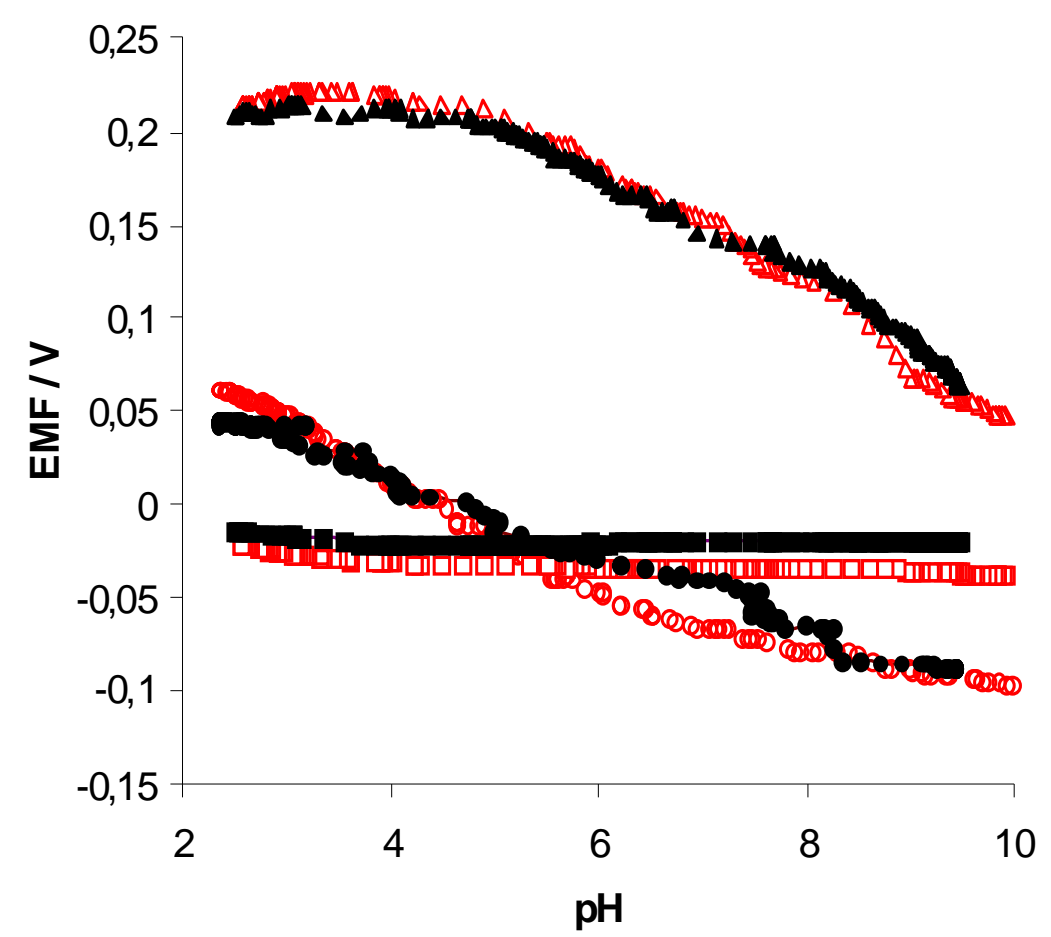

Figure 2. Potential vs pH curves obtained by electrodes containing: (0) ligand;

$(\Delta)$ ligand $+50 \%$ TDDMACl; $(\square)$ ligand $+50 \% \mathrm{~K}-\mathrm{TpClPB}$ ( $\mathrm{pH}$ was changed from 9.5 to 2.5 );

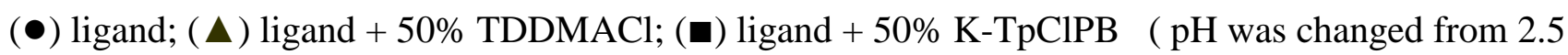
to 9.5 ). Measuring conditions - see part 2.3.

\subsection{Potentiometric Responses of Diureidocalixarene-containing ISE towards Benzoic Acid}

Diureido derivatives of calix[4]arenes in 1,3-alternate conformer represents ionophores with one anionic binding site (Figure 1). It has been already reported that similar calixarene with two ureido moiety showed strongest interaction in one organic phase with benzoate ions [9]. In the work presented, diureidocalixarene has been studied as the ionophore of ISE destined for determination of benzoic acid in its undissociated form.

The measurements were performed in solution of $1.0 \times 10^{-2} \mathrm{M} \mathrm{NaHSO}_{4}$. The interaction between investigated ionophore and sulfate anions have been studied. The electrodes showed no response towards sulfate anions in concentration range from $1.0 \times 10^{-6} \mathrm{M}$ to $5.0 \times 10^{-3} \mathrm{M}$ in the solution of $1.0 \mathrm{x}$ $10^{-2} \mathrm{M}$ citric buffer, $\mathrm{pH}=3.0$. On the basis of this results we used this salt in background solution.

The measurements were carried out at $\mathrm{pH}=3.0$ in which electrodes showed best potentiometric response (Figure 3). Under these conditions benzoic acid is present in $85 \%$ as neutral compound (pKa = 4.21). Also, acidic solution diminished the competition caused by $\mathrm{OH}^{-}$complexation. The $\mathrm{pH} 6.2$, 
where benzoic acid exists in dissociated form, was unsuitable for potentiometric measurements with using diureidocalixarene -ISE, mainly because of strong competition with $\mathrm{OH}^{-}$(results are not shown).

The research presented concerned the interaction between neutral carrier - diureidocalix[4]arene and neutral analyte - benzoic acid. In such a case the optimalization of membrane composition is rather puzzling problem.

The addition of $50 \mathrm{~mol} \%$ vs ionophore of lipophilic cationic sites TDDMA ${ }^{+}$increased the membrane response towards benzoic acid (Figure 3 ). On the other hand, the addition of $50 \mathrm{~mol} \%$ vs ionophore of lipophilic anionic sites $\mathrm{TClPB}^{-}$caused lack of responses towards benzoic acid ( results are not showed).

It might be concluded that the membranes which showed the highest responses towards $\mathrm{pH}$ changes

(Figure 2), displayed the strongest responses towards benzoic acid ( Figure 3). The similar phenomenon was observed in the case of calix[4]pyrrole- ISE derivatives used for potentiometric determination of nitrophenol isomers existing in the neutral forms [28].

The presence of lipophilic cationic sites $\mathrm{TDDMA}^{+}$in the membrane doped with diureidocalix[[4]arene, decreased its resistance, but also might facilitated the interaction with benzoic acid.

The research on the elucidation of the role of $\mathrm{TDDMA}^{+}$in the potentiometric responses of diureidocalix[[4]arene -ISE will be carried on in our laboratory.

The macrocyclic hexamine-ISE [29] and diureidocalixarene-ISE showed comparable detection limits (in the range of $10^{-4} \mathrm{M}$ of benzoic acid). The optimum $\mathrm{pH}$ values of benzoic acid solutions to be measured with macrocyclic hexamine-ISE and diureidocalix[4]arene-ISE were 5.0 and 3.0, respectively. The major of soft drinks have rather low $\mathrm{pH}$. Therefore, the $\mathrm{pH}$ adjustment could be avoided for the determinations of benzoic acid contents in soft drinks using diureidocalix[4]areneISE.

Based on the results obtained, diureidocalixarene can be added to the group of receptors, which are able to recognize the neutral molecules potentiometricaly.

Generation of potentiometric signals of ISEs in the presence of neutral forms of phenol derivatives, have been already reported. This phenomenon was observed for electrodes incorporated with macrocyclic polyamine [30], calix[4]pyrrole [28, 32, 33] and corrole [34].

For these electrodes two steps mechanism of potentiometrc response generation was proposed [35]. First step concerns formation of supramolecular host-guest complex between ionophore and analyte by hydrogen bonding. In the consequence, proton from $\mathrm{OH}$ of phenolic group involved in hydrogen bonding become more acidic and dissociate at the organic membrane / aqueous interface (second step).

The same mechanism might be proposed for the phenomenon investigated in this work. Diureidocalix[4]arene creates at the membrane / aqueous interface supramolecular complex with undissociated benzoic acid. Hydrogen bonds might be formed between hydrogen atoms from ureido groups of ionophore and oxygen atoms from carboxlic group of benzoic acid. $\pi$ - $\pi$ interaction between phenyl rings of analyte and ionophore also can play some role. The creation of complex based on hydrogen bonds formation cause increase of acidity of proton from benzoic acid molecule. Therefore this proton can dissociate at $\mathrm{pH} 3.0$ and can be shifted from the surface of the membrane towards water 
solution surface. As a consequence, the charge separation at the organic / aqueous interfaces is created and anionic potentiometric signal is generated.

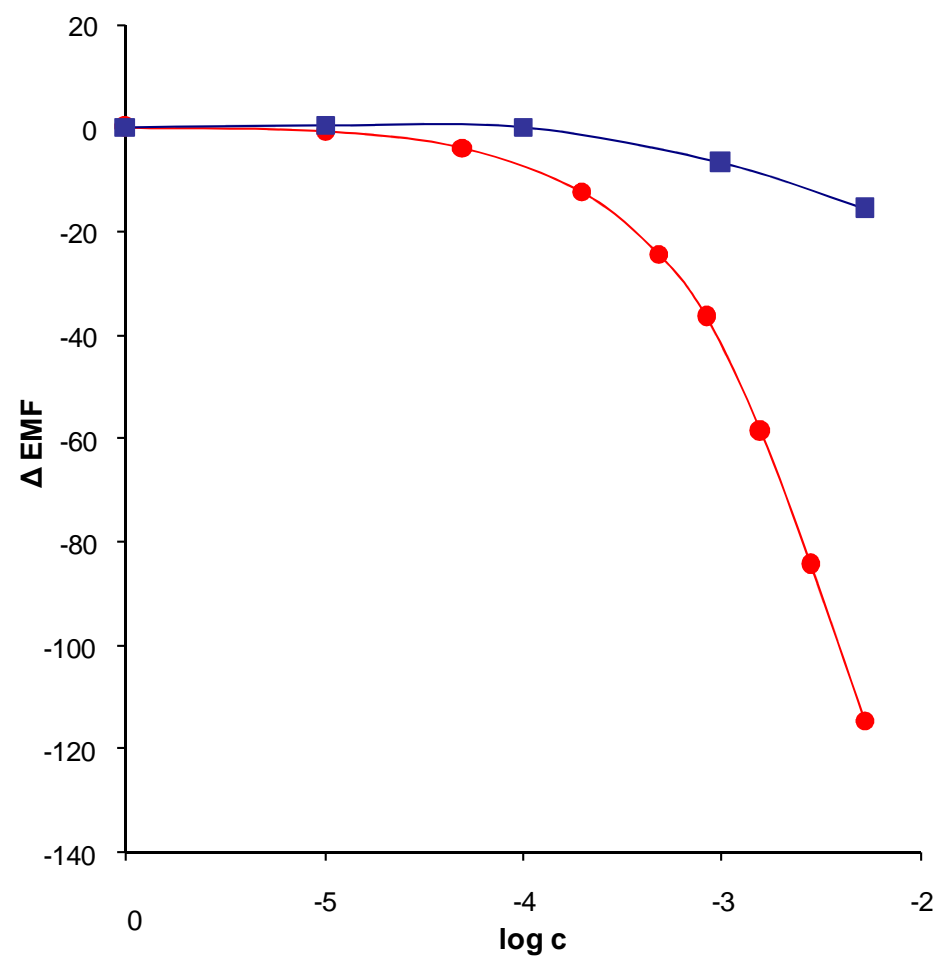

Figure 3. Potential changes vs. concentration curves obtained for ISEs doped with ligand (a) and ligand + 50\% TDDMACl $(\bullet)$. Measurements were taken in $1.0 \times 10^{-2} \mathrm{M} \mathrm{NaHSO}_{4} \mathrm{pH} 3.0(\mathrm{n}=4 ; 0,31<$ $\mathrm{SD}<15,46)$.

\subsection{Time of Response of Diureidocalix[4]arene ISE towards Benzoic Acid}

A response time is important parameter which characterize ISEs. Figure 4 illustrates a representative plot of the potential changes vs time for electrode with diureidocalix[4]arene and lipophilic salt TDDMACl after additions aliquots of $1.0 \times 10^{-2} \mathrm{M}$ aqueous stock solution of benzoic acid. The electrode responses towards changes in concentration of benzoic acid were relatively fast (ca. $100 \mathrm{~s}$ ) within the whole concentration range, when we assume response mechanism including more than one step, which are necessary in the case of uncharged analytes.

\subsection{Potentiometric Selectivity of Electrode Incorporating Diureidocalix[4]arene}

Potentiometric selectivity coefficient defines the ability of the ISE to differentiate a particular (primary) ion from others (interfering ions) [18-20]. Matched potential method (MPM) was used to determine of these parametrs. In this method the selectivity coefficient is defined as the activity (concentration) ratio of the primary ion and interfering ion which give the same potential change in a reference solution.

This method can be used in case of differences in charge number between primary and interfering ions and don't require Nernstain responses to the activity (concentration) of primary or interfering ions. 
This is only one method suitable for determination of selectivity coefficients concerning the neutral compounds.

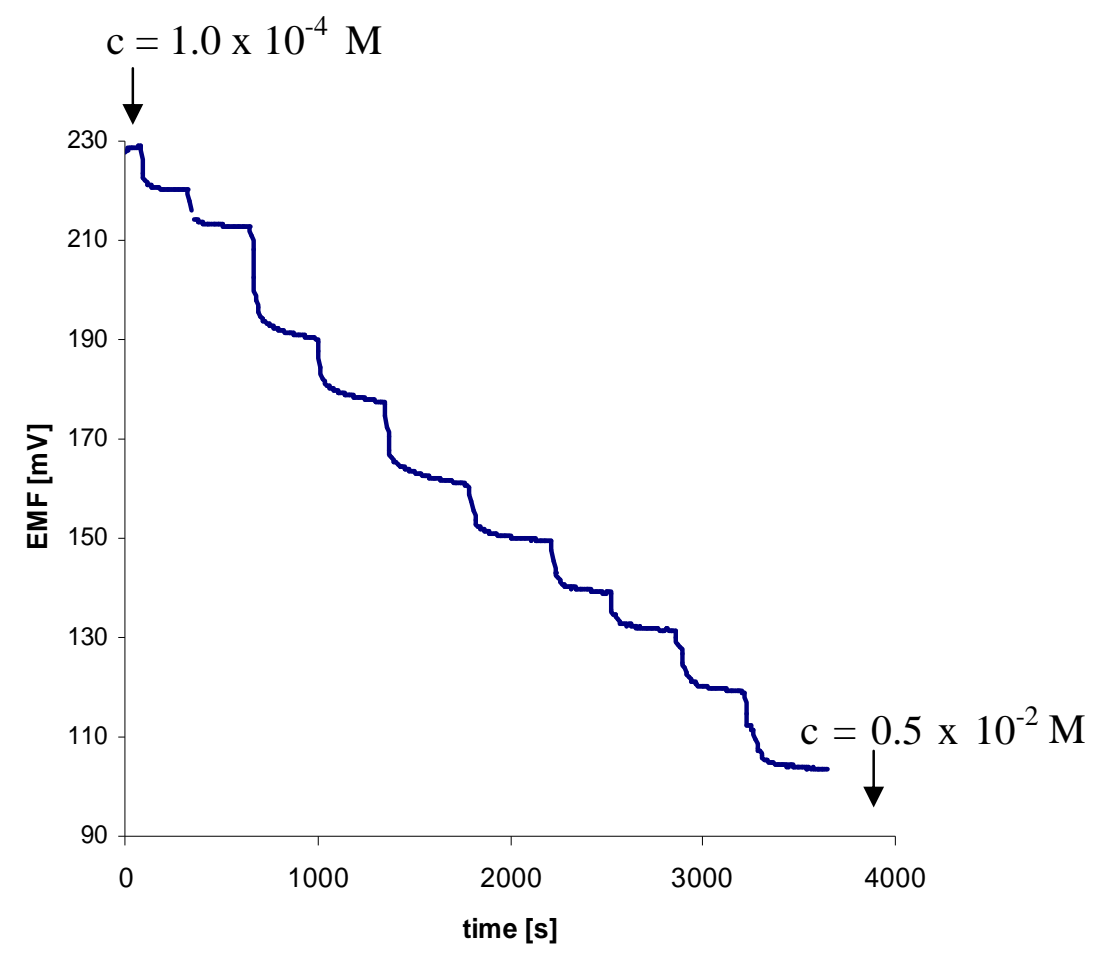

Figure 4. Response time towards benzoic acid addition. Aliquot of the stock solution $1.0 \times 10^{-2} \mathrm{M}$ analyte was added to $100.0 \mathrm{ml} 0.01 \mathrm{M} \mathrm{Na}_{2} \mathrm{SO}_{4}, \mathrm{pH} 3.0$ to increase acid concentration from $1.0 \times 10^{-4}$ $\mathrm{M}$ to $0.5 \times 10^{-2} \mathrm{M}$.

Solution $1.0 \times 10^{-3} \mathrm{M}$ of benzoic acid and $1.0 \times 10^{-2} \mathrm{M} \mathrm{NaHSO}_{4}$ was used as background. For the calculation of selectivity coefficients, $\triangle \mathrm{EMF}=-2.0 \mathrm{mV}$ was used. The calculated values of selectivity coefficients are summarized in Table 1 . These results showed that electrodes studied are selective towards benzoic acid in the presence of several interferents commonly occurring in beverages. According to the selectivity coefficient values the interfering substances could be ordered as follows:

$$
\text { chloride }>\text { phosphate }>>\text { ascorbate } \approx \text { acetate } \approx \text { citrate } \approx \text { glucose }
$$

The several potentiometric sensors destined for benzoic acid and/or benzoate determination have been already reported, macrocyclic polyamine -ISE [30], Pt $|\mathrm{Hg}| \mathrm{Hg}_{2}$ (benzoate) $)_{2} \mid$ graphite) [36], just to name a few.

ISEs doped with diureidocalix[4]arene and macrocyclic polyamine showed similar selectivity. The major interferents (citrate and acetate ions) present in the soft drinks possess only very small effect on the benzoic acid determination (Table 1). On the other hand, the $\mathrm{Pt}|\mathrm{Hg}| \mathrm{Hg}_{2}$ (benzoate) (braphite $_{2}$ electrode can not be used for the direct determination of benzoic acid because of serious interference caused by chloride anions [36]. 
Table 1. Potentiometric selectivity coefficients of ISEs determined by matched potential method.

\begin{tabular}{c|c}
\hline Interferent, $j$ & $\begin{array}{c}\log K_{B e n z, j}^{M P M} \\
\Delta \mathrm{EMF}=-2 \mathrm{mV}\end{array}$ \\
\hline Chloride & $-0,42$ \\
Ascorbate & $<<0$ \\
Phosphate & $-1,22$ \\
Acetate & $<<0$ \\
Citrate & $<<0$ \\
Glucose & $<<0$
\end{tabular}

The $\log \mathrm{K}$ values were determined in the background solution consists of $1.0 \times 10^{-2} \mathrm{M} \mathrm{NaHSO}_{4}$ and $1.0 \times 10^{-3}$ $\mathrm{M}$ benzoic acid $\mathrm{pH} 3.0$ as background and calculated for the $\triangle \mathrm{EMF}=2 \mathrm{mV}$. Standard deviations: $0.02<\mathrm{SD}<$ 0.28 .

\subsection{Determination of Benzoic Acid in Breverage.}

In order to display the potential applicability of diureidocalix[4]arene ISEs they were used for the direct determination of benzoic acid content in investigated lemon soft drink. The determination was done using the standard addition method.

The selectivity coefficients describing above showed no interferences from other compounds presented in this beverage. Nevertheless the standard addition method was used to minimize the matrix effect. For this purpose beverage was initially degassed and diluted 10-fold with $1.0 \times 10^{-2} \mathrm{M} \mathrm{Na}_{2} \mathrm{SO}_{4}$.

The results were obtain from 3 electrodes and 3 repetitions. The determined concentration of benzoic acid was $1.6 \pm 0.1 \times 10^{-4} \mathrm{M}$ in diluted sample which gives $1.6 \pm 0.1 \times 10^{-3} \mathrm{M}$ of benzoic acid in beverage. This concentration is equal $0.20 \pm 0.01 \mathrm{~g} / \mathrm{L}$ of this preservative. This amount corresponds with benzoate contents determined in lemon soda drink (Sprite) by HPLC - 237.4 \pm 3.1 ppm [36] and to contents define by the Regulation of the Minister of Health in Poland - $0.15 \mathrm{~g} / \mathrm{L}$ maximum [37].

\subsection{Recovery Test}

The recovery test was successfully performed by determination of milimolar amounts of benzoic acid in artificial juice matrix (for composition see Material and Methods).

The results are showed in Table 2 and demonstrate that the components of artificial juice matrix do not interfere significantly with the benzoic acid determination. The recovery values of $100.8-107.7 \%$ were obtained for determination of: $0.479,0.741,1.000$ and $1.380 \mathrm{mM}$ of benzoic acid. 
Table 2. Recovery test of benzoic acid added to the artificial juice matrix $(n=8)$.

\begin{tabular}{ccc}
\hline $\begin{array}{c}\text { Concentration } \\
\text { known }(\mathrm{mM})\end{array}$ & $\begin{array}{c}\text { Concentration found } \\
(\mathrm{mM})\end{array}$ & Recovery $(\%)$ \\
\hline 0.479 & $0.516 \pm 0.042$ & $107.7 \pm 8.7$ \\
0.741 & $0.760 \pm 0.031$ & $102.6 \pm 4.1$ \\
1.000 & $1.016 \pm 0.033$ & $101.6 \pm 3.3$ \\
1.380 & $1.391 \pm 0.028$ & $100.8 \pm 2.1$
\end{tabular}

\subsection{Conclusions}

The liquid membrane electrode doped with diureidocalix[4]arene and additionally with $50 \mathrm{~mol} \%$ vs ionophore of lipophilic cationic salt, tridodecylmethylammonium chloride, can be used for the direct determination of un-dissociated benzoic acid in beverages. The proposed ISE was effective regarding the following parameters: the sufficient detection limit $2.0 \times 10^{-4} \mathrm{M}$, good selectivity towards substances commonly occurred in drink samples, reversibility and short response time.

Therefore, the diureidocalix[4]arene-ISE might be recommended for the direct potentiometric determination of un- dissociated benzoic acid in beverages.

\section{Acknowledgements}

The work presented was realized in the framework of COST working group (D31/0021/05), grant no: PBZ KBN-098/T09/2003 and research project MSM 6046137301.

\section{References and Notes}

1. Ikeda A.; Shinkai S.; Novel cavity design using calix[n]arene skeletons: toward molecular recognition and metal binding. Chem. Rev, 1997, 97, 1713-1734.

2. Ganjali, M. R.; Norouzi, P.; Rezapour, M.; Faridbod, F.; Pourjavid, M. R.; Supramolecular based membrane sensors. Sensors, 2006, 6, 1018-1086

3. Gutsche, C.D.; Iqgal, M.; Nam, K.S.; See, K.; Alam, I.; Conformational and complexational characteristics of calixarenes. Pure and Appl. Chem. 1988, 60, 483-488.

4. Chung, T.D.; Kim, H.; Electrochemistry of calixarene and analytical applications. J. Incl. Phenom. Macro. 1998, 32, 179-193.

5. van Dienst, E.; Bakker, W.I.I.; Engbersen, J.F.J.; Verboom, W.; Reinhoudt, D.N.; Calixarenes, chemical chameleons. Pure and Appl. Chem. 1993, 65, 387-392.

6. Stastny, V.; Lhotak, P.; Michlova, V.; Stibor, I.; Sykora, J.; Novel biscalix[4]arene-based anion receptors. Tetrahedron, 2002, 58, 7207 - 7211.

7. Lhoták, P.; Calixarene-based receptors for anion sensing. Topics in Current Chemistry, 2005, Springer Verlag Vol. 255, p. 65-96.

8. Beer, P.D.; Gale P.A.; Hesek, D.; A neutral upper to lower rim linked bis-calix[4]arene receptor that recognises anionic guest species. Tetrahedron Lett. 1995, 5, 767-770.

9. Budka, J.; Lhotak, P.; Michlova V.; Stibor, I.; Urea derivatives of calix[4]arene 1, 3-alternate: an anion receptor with profound negative allosteric effect. Tetrahedron Lett., 2001, 42, 1583 - 1586. 
10. Wibbertmann, A., Kielhorm, J.; Koennecker, G.; Gelsdorsf, I.; Meller, C.; Benzoic acid and sodium benzoate. Concise International Chemical Assessment, document no. 26, Geneva, 2000

11. Basan H.; Dincer Z.; Goger N.G.; Derivative UV spectrophotometric method for the simultaneous determination of ambroxol and preservatives in syrup. Chem. Anal. (Warsaw), 2005, 50, 465.

12. Hamano, T.; Mitsuhashi, Y.; Aoki, N.; Semma, M.; Ito, Y.; Enzymatic metod for the spetrophotometric determination oc benzoic acid in soy sauce and pickles. Analyst 1997, 122, 259-262.

13. Dong, C.; Wang, W. Headspace solid-phase microextraction applied to the simultaneous determination of sorbic and benzoic acids on beverages. Anal. Chim. Acta, 2006, 562, 23-29.

14. Pan, Z.; Wang, L., Mo, W.; Wang, C.; Hu., W.; Zhang, J. Determination of benzoic acid in soft drinks by gas chromatography with on-line pyrolytic methylation technique. Anal. Chim. Acta, 2005, 545, 218-223.

15. Tfouni, S. A V.; Toledo, M. C. F.; Determination of benzoic and sorbic acids in Brazilian food. Food Control. 2002, 13, 117-123.

16. Ferreira, I. M. P. L. V. O.; Mendes, E.; Brito, P.; Ferreira, M. A. Simultaneous determination of benzoic and sorbic acids in quince jam by HPLC. Food Research International, 2000, 33, $113-$ 117.

17. Walker, J. C.; Zaugg, S. E.; Walker, E. B.; Analysis of beverages by capillary electrophoresis. J. Chromatogr. A. 1997, 781, 481-485.

18. Buck, R.P.; Lindner E.; Recomendations for nomenclature of ion-selective electrodes (IUPAC Recommendation 1994). Pure and Appl. Chem. 1994, 66, 2527-2536.

19. Umezawa, Y.; Umezawa, K.; Sato, H.; Selectivity coefficients for ion-selective electrodes: recommended methods for reporting $\mathrm{K}_{\mathrm{A}, \mathrm{B}}^{\mathrm{pot}}$ values. Pure and Appl. Chem., 1995, 67, 507 - 510.

20. Tohda, K.; Dragoe, D.; Shibata, M.; Umezawa, Y.; Studies on the matched potential method for determining the selectivity coefficients of ion-selective electrodes based on neutral ionophores: experimental and theoretical verification. Analytical Sciences 2001, 17, 733 - 743.

21. www.hort.purdue.edu, www.fineli.fi

22. Bader, M.; A systematic approach to standard addition methods in instrumental analysis. J. Chem. Educ., 1980, 57, 703 - 706.

23. Christian G.D.; Analytical chemistry, J. Wiley and Sons 1994; pp. 370 - 379

24. Amemiya, S.; Buhlmann, P., Pretsch, E.; Rusterholz, B.; Umezawa, Y.; Cationic or anionic sites? Selectivity optimization of ion-selective electrodes based on charged ionophores. Anal. Chem. 2000, 72, 1618-1631.

25. Buhlmann, P.; Yajima, S.; Tohda, K.; Umezawa, K.; Nishizawa, S.; Umezawa, Y.; Studies on the phase boundaries and the significance of ionic sites of liquid membrane ion-selective electrodes. Electroanalysis. 1995, 7, 811-816.

26. Buhlmann, P., Yajima, S.; Tohda, K.; Umezawa, Y.; EMF response of neutral-carrier based ionselective field efect transistors with membranes free of ionic sites. Electrochim. Acta. 1995, 40, 3021-3027.

27. Bakker, E.; Buhlmann, P.; Pretsch, E.; The phase-boundary potential model. Talanta. 2004, 62, 843-860. 
28. Radecki, J.; Radecka, H.; Piotrowski, T.; Depraetere, S.; Dehaen, W.; Plavec, J.; Interface hostguest interaction between calix[4]pyrrole and neutral derivatives of phenol as the base for their potentiometric discrimination. Electroanalysis 2004, 16, 2073 - 2081.

29. Kral, V.; Sessler, J.L.; Shishkanova, T.V.; Gale, P.A.; Volf, R.; Molecular recognition at an organic-aqueous interface: heterocalixarenes as anion bindings agents in liquid polymeric membrane ion-selective electrodes. J. Am. Chem. Soc., 1999, 121, 8771 - 8775.

30. Bulgariu, L.; Radecka, H.; Pietraszkiewicz, M.; Pietraszkiewicz, O.; Potentiometric response of liquid membrane electrode incorporated with macrocyclic polyamine towards benzoate. Anal. Let. 2003, 36, 1325 - 1334.

31. Piotrowski, T.; Szymańska, I.; Radecka, H.; Radecki, J.; Pietraszkiewicz, M.; Pietraszkiewicz, O. ; Wojciechowski, K.; Influence of substituents in nitrogen atoms in macrocyclic polyamnine incorporated into poly(winyl chloride) matrix liquid membrane on its potentiometric response to neutral phenols. Electroanalysis, 2000, 12, 1397-1402.

32. Nechita, M.T.; Lotrean, S.; Radecki, J.; Radecka, H.; Depreatere, S.; Dehaen, W.; Potentiometric response of liquid membrane electrodes incorporated with new calix[4]pyrrole and pyrrole derivatives towards neutral nitrophenol. Pol. J. Food Nutr. Sci. 2003, 12, 81-87.

33. Piotrowski, T.; Radecka, H.; Radecki, J.; Depreatere, S.; Dehaen, W.; Potentiometric response of calix[4]pyrrole liquid membrane electrode towards neutral nitrophenols. Electroanalysis 2001, 13, 342-346.

34. Radecki, J.; Stenka, I.; Dolusic, E.; Dehaen, W.; Plavec, J.; Potentiometric discrimination of neutral forms of nitrophenol isomers by liquid membrane electrodes incorporated with corroles. Comb. Chem. High Throughput Screen. 2004, 7, 375-381.

35. Radecki, J.; Dehaen, W.; Nitrogen-containing macrocycles as host molecules for the recognition of undissociated phenol derivatives: mechanizm of potentiometric signal generatin. Comb. Chem. High Throughput Screen. 2006, 9, 399-406.

36. Pezza L.; Santini A.O.; Pezza H.R.; Melios C.B.; Ferreira V.J.F.; Nasser A.L.M.; Benzoate ion determination in beverages by using a potentiometric sensor immobilized in a graphite matrix. Anal. Chim. Acta, 2001, 433, $281-288$

37. Regulation of the Minister of Health of the $27^{\text {th }}$ December 2000 on the list of permissible levels of the food additives and foreign substances added to food products and stimulants as well as contaminamts that are likely to occur in food products and stimulants. Official Journal of Laws No 9 , item 72 of 2001

(C) 2007 by MDPI (http://www.mdpi.org). Reproduction is permitted for noncommercial purposes. 